\title{
Embodied Cognition: A Challenging Road for Clinical Neuropsychology
}

\author{
Juan F. Cardona* \\ Instituto de Psicología, Universidad del Valle, Santiago de Cali, Colombia
}

Keywords: embodied cognition, clinical neuropsychology, neuropsychological tests, modularity of mind, cognitive assessment

Clinical neuropsychology $(\mathrm{CN})$ has clearly emerged as a diagnostic discipline, influenced by disembodied and localizationist-connectionist approaches. In this sense, cognition has been understood as a relatively isolated link of perception and movement. The classic model "perception $\rightarrow$ cognition $\rightarrow$ action" has guided the design of instruments and the interpretation of the results in pathological conditions of the central nervous system. This trend has been maintained over time thanks to the convergence of the localizationist approach and computational models of information processing adopted by CN (Shallice, 1988).

Recently, embodied cognition (EC) has put the sensory-motor system on the stage of human cognitive neuroscience (Willems and Francken, 2012; Freund et al., 2016). EC proposes that the brain systems underlying perception and action are integrated with cognition in bidirectional pathways (Borghi and Pecher, 2011; Ibáñez et al., 2013; Cardona et al., 2014), highlighting their connection with bodily (Gallese and Lakoff, 2005; Gallese and Sinigaglia, 2011) and emotional (Niedenthal, 2007; De Jaegher et al., 2010) experiences, leading to research programs aimed at demonstrating the influence of action on perception (Proffitt, 2006; Creem-Regehr and Kunz, 2010; Witt, 2011) and high-level cognition (Barrett et al., 2007; Goldin-Meadow and Beilock, 2010; Ibáñez and Manes, 2012).

Embodied cognition (EC) findings are gradually leading to an integrative view of mental functions and their interdependence with the context, questioning the validity of the computational paradigm and the localizationalist doctrine in explaining brain functioning and its correspondence with complex behavior. These findings have also given a scientific character to the study of bodily

OPEN ACCESS

Edited by:

P. Hemachandra Reddy,

Texas Tech University Health Sciences

Center, United States

Reviewed by:

Asgar Zaheer,

University of Missouri, United States

*Correspondence:

Juan F. Cardona

felipe.cardona@correounivalle.edu.co

Received: 06 June 2017 Accepted: 10 November 2017 Published: 22 November 2017

Citation:

Cardona JF (2017) Embodied Cognition: A Challenging Road for Clinical Neuropsychology.

Front. Aging Neurosci. 9:388. doi: 10.3389/fnagi.2017.00388 experience in the analysis of brain function. The continuous accumulation of evidence from EC has had both theoretical and experimental influence and is expected to ultimately impact the clinical field. This article presents some of the main challenges that neuropsychology faces in integrating $\mathrm{EC}$ in its clinical assessment and diagnosis processes.

\section{CEREBRAL BOUNDARIES: ROOTS OF NEUROPSYCHOLOGICAL ASSESSMENT}

Historically, perception and movement have been separated from cognition. The events that occurred in the nineteenth century are a turning point in the parsed study of the functions of the nervous system. The neurophysiology of the motor and sensory processes was consolidated from the pioneering findings of Bell (1811) and Magendie (1822). With the same importance in CN, Dax (1836) (See, Cubelli and Montagna, 1994; Manning and Thomas-Anterion, 2011) and Broca (1861) reported the correspondence between alterations in language production and damage to the left frontal zone of the brain, consolidating the localizationist approach in the explanation of cognitive organization.

Although alternative proposals such as the equipotential theory (Lashley, 1929) that emphasized the interactivity of the whole brain (holism) emerged, localizationalist doctrine and its methods were extended at an accelerated rate to the study of various cognitive functions, making it impossible to trace a single line of scientific development from that period. 
In this way, the diagnostic procedures and methods of investigation in $\mathrm{CN}$ were directly influenced by localizationist theory. Pioneering neuropsychologists, including Henry Hecaen, Oliver Zangwill, Hans-Lukas Teuber and Brenda Milner, worked together with neurosurgeons to develop reliable tools that would discriminate patients with brain lesions from normal controls (Halstead, 1947; Hartlage, 1966). The approach between behavioral neurology and psychometrics led to the selection of sensitive tests to find anatomic-clinical correspondences contained in classical neuropsychological batteries, such as the Halstead-Reitan (Halstead, 1947; Reitan and Wolfson, 1985, 1993) Luria-Nebraska (Golden et al., 1980) and other instruments used in clinical practice (Strauss et al., 2006).

A methodology associated with strict localizationism has been the double dissociation (Teuber, 1955; Weiskrantz, 1968, 1991), which is shown when lesions in area $\mathrm{A}$ affect function $\mathrm{X}$ more than function $\mathrm{Y}$, while lesions in area $\mathrm{B}$ affect function $\mathrm{Y}$ more than function $\mathrm{X}$. This type of approach responds to a logic of "effect $=$ structure" and suggests that performance in a given task depends on a specialized area of the cerebral cortex (Pribram, 1971).

The convergence between the modular theory of Fodor (1983) and the advent of neuroimaging techniques gave credence to this fragmented brain organization, leading to the overvaluation of strong dissociations between brain functions such as hearing (Peretz et al., 1994; Peretz and Coltheart, 2003), memory (Moscovitch, 1995; Moscovitch and Nachson, 1995) and language (Warrington and Shallice, 1984; Warrington and McCarthy, 1987; Pinker and Ullman, 2002; Crutch and Warrington, 2003) and to the selection of numerous tasks aimed at inferring the delimited location of brain damage that still have clinical utility in the recognition of cognitive alterations (Strauss et al., 2006; Lezak, 2012). Although the development of measuring instruments represented an advance in the $\mathrm{CN}$, many tasks cannot easily be extrapolated to activities of daily living. To overcome this problem, important advances have been made in the development of tests that have greater ecological validity, establishing a better relationship between the evaluation and the interpretation of the results, taking into account the impact that cognitive alterations have in the everyday activities of patients (Wilson et al., 1985, 1987; McDonald et al., 2003; Torralva et al., 2009). However, perception and action are still isolated from cognitive domains.

\section{AN INTEGRATIVE VIEW OF BRAIN-CONTEXT INTERACTION}

The idea of coupling between mental processes is not new in $\mathrm{CN}$. In fact, clinical evidence from the pioneering work of Gonzalo (1950) (see Gonzalo-Fonrodona, 2009) and Goldberg $(1989,1995)$ suggested a dynamic organization of the cerebral cortex underlying sensory, cognitive and motor integration. These findings have been supported by cross-modal studies (Fuster et al., 2000; Ghazanfar and Schroeder, 2006; Driver and Noesselt, 2008; Spence and Parise, 2012) that show interactivity and coupling in processes such as vision (Klapetek et al., 2012), hearing (Parise and Spence, 2012), somato-perception and the chemical senses (Hanson-Vaux et al., 2013).

However, it was the discovery of mirror neuron system (MNS) in the human brain (Rizzolatti and Craighero, 2004) that facilitated EC to show the interaction of language and motor system (Rizzolatti and Arbib, 1998; Pulvermuller, 2005; Arévalo et al., 2015). In light of these findings, neuropsychological exploration in diseases traditionally classified as movement disorders has uncovered a compromise in action language processing (Bak, 2013), such as corticobasal degeneration (Cotelli et al., 2006; Silveri and Ciccarelli, 2007), Huntington's disease (Peran et al., 2004; Kargieman et al., 2014), progressive supranuclear palsy (Bak et al., 2006; Cotelli et al., 2006), amyotrophic lateral sclerosis (Neary et al., 2000; Bak et al., 2001; Bak and Hodges, 2004) and Parkinson's disease (Boulenger et al., 2008; Cardona et al., 2013, 2014), revealing the compromise of language even at an early stage of pathology and becoming a potential early marker in the specific case of Parkinson's disease.

Additionally, under the EC framework, the study of emotional processing, understood as a multilevel and context-dependent domain (Barrett et al., 2007), has been given a prominent place, making it clear how neurodegenerative pathologies (Ibáñez and Manes, 2012) and neuropsychiatric disorders (Ibáñez et al., 2011) present notorious difficulties when integrating contextual cues into ecological cognitive tasks.

\section{CONCLUSION}

Embodied cognition (EC) findings in the area of neuropsychology demonstrate that interactivity and multimodality are fundamental features of brain functioning and that contextual interdependence can be a crucial factor in regard to bringing about effective interventions, opening the door to new research in various clinical conditions. This premise reflects a methodological imperative for $\mathrm{CN}$.

First, the model of cerebral functioning that guides neuropsychological intervention should be strengthened in consensus. In this sense, EC invites an integrative vision of mental processes and encourages the development of new methods that complement the approaches of cognitive functions. Although current assessment tools are sensitive and reliable in detecting cognitive deficits associated with central nervous system disorders, the design and integration of multimodal, emotional and contextual processing measures may have more ecological validity than other measures (Franzen and Wilhelm, 1996; Chaytor and Schmitter-Edgecombe, 2003; Rabin et al., 2007).

Second, the findings of linkages between the language and motor systems could guide the establishment of clinical guidelines that include the evaluation of the language of action in neurodegenerative motor pathologies and could also provide new perspectives and intervention strategies that may delay cognitive impairment in these clinical pictures. This suggestion is based on the positive results of cognitive stimulation in reducing 
executive and functional deficits in patients with Parkinson's disease (Sinforiani et al., 2004; Sammer et al., 2006). In this way, it is necessary to clarify the different deficits in language processing to propose cross-modal treatments that facilitate the attenuation of motor deficits. Likewise, the establishment of the relationship between the language and motor systems leads to the need to verify the presence of other couplings between the sensory-motor system and other domains of cognition to enable the establishment of rehabilitation programs.

Embodied cognition (EC) also provides new perspectives and intervention strategies in other areas of mental health. Some proposals have emerged in clinical psychology (Zatti and Zarbo, 2015) and psychiatry (Fuchs, 2009; Fuchs and Schlimme, 2009) in which classical theories of cognition presented serious limitations in explaining the appearance of nonunderlying behavioral alterations to specific brain injuries and in which experience and environmental factors play fundamental roles.

The integration of experience and context into the triad "perception, cognition and action" has been previously accepted

\section{REFERENCES}

Arévalo, A., Baldo, J., González-Perilli, F., and Ibáñez, A. (2015). Editorial: What can we make of theories of embodiment and the role of the human mirror neuron system? Front. Hum. Neurosci. 9:500. doi: 10.3389/fnhum.2015.00500

Bak, T. H. (2013). The neuroscience of action semantics in neurodegenerative brain diseases. Curr. Opin. Neurol. 26, 671-677. doi: 10.1097/WCO.0000000000000039

Bak, T. H., and Hodges, J. R. (2004). The effects of motor neurone disease on language: further evidence. Brain Lang. 89, 354-361. doi: 10.1016/S0093-934X(03)00357-2

Bak, T. H., O’Donovan, D. G., Xuereb, J. H., Boniface, S., and Hodges, J. R. (2001). Selective impairment of verb processing associated with pathological changes in Brodmann areas 44 and 45 in the motor neurone disease-dementia-aphasia syndrome. Brain 124. 103-120. doi: 10.1093/brain/124.1.103

Bak, T. H., Yancopoulou, D., Nestor, P. J., Xuereb, J. H., Spillantini, M. G., Pulvermüller, F., et al. (2006). Clinical, imaging and pathological correlates of a hereditary deficit in verb and action processing. Brain 129. 321-332. doi: 10.1093/brain/awh701

Barrett, L. F., Lindquist, K. A., and Gendron, M. (2007). Language as context for the perception of emotion. Trends Cogn Sci. 11, 327-332. doi: 10.1016/j.tics.2007.06.003

Bell, C. (1811). Idea of a New Anatomy of the Brain Submitted for the Observation of his Friends. London: Strahan and Preston.

Borghi, A. M., and Pecher, D. (2011). Introduction to the special topic embodied and grounded cognition. Front. Psychol. 2:187 doi: 10.3389/fpsyg.2011.00187

Boulenger, V., Mechtouff, L., Thobois, S., Broussolle, E., Jeannerod, M., and Nazir, T. A. (2008). Word processing in Parkinson's disease is impaired for action verbs but not for concrete nouns. Neuropsychologia 46, 743-756. doi: 10.1016/j.neuropsychologia.2007.10.007

Broca, P. (1861). Remarques sur le siege de la faculte du langage articule; suivies d'une observation d'aphemie. Bull. Soc. Anatom. Paris 6, 330-357.

Cardona, J. F., Gershanik, O., Gelormini-Lezama, C., Houck, A. L., Cardona, S., Kargieman, L., et al. (2013). Action-verb processing in Parkinson's disease: new pathways for motor-language coupling. Brain Struct. Funct. 218, 1355-1373. doi: 10.1007/s00429-013-0510-1

Cardona, J. F., Kargieman, L., Sinay, V., Gershanik, O., Gelormini, C., Amoruso, L., et al. (2014). How embodied is action language? Neurological evidence from motor diseases. Cognition 131, 311-322. doi: 10.1016/j.cognition.2014.02.001 in the understanding of brain development in childhood. However, EC findings show that the adult brain remains context-dependent and that experience directly impacts both structural and brain functioning throughout life. Although localizational and computational models have made numerous contributions to the development of clinical practice, EC highlights the role of the body and the sensory-motor experience, allowing a broader vision and a better understanding of cognitive processes under both normal and pathological conditions.

\section{AUTHOR CONTRIBUTIONS}

The author confirms being the sole contributor of this work and approved it for publication.

\section{ACKNOWLEDGMENTS}

This work was partially supported by grant from Universidad del Valle (Research Grant Scheme: 5278).

Chaytor, N., and Schmitter-Edgecombe, M. (2003). The ecological validity of neuropsychological tests: a review of the literature on everyday cognitive skills. Neuropsychol. Rev. 13, 181-197. doi: 10.1023/B:NERV.0000009483.91468.fb

Cotelli, M., Borroni, B., Manenti, R., Alberici, A., Calabria, M., Agosti, C., et al. (2006). Action and object naming in frontotemporal dementia, progressive supranuclear palsy, and corticobasal degeneration. Neuropsychology 20, 558-565. doi: 10.1037/0894-4105.20.5.558

Creem-Regehr, S. H., and Kunz, B. R. (2010). Perception and action. Wiley Interdiscip. Rev. Cogn. Sci. 1, 800-810. doi: 10.1002/wcs.82

Crutch, S. J., and Warrington, E. K. (2003). The selective impairment of fruit and vegetable knowledge:amultiple processing channels account of fine-grain category specificity. Cogn. Neuropsychol. 20, 355-372. doi: $10.1080 / 02643290244000220$

Cubelli, R., and Montagna, C. G. (1994). A reappraisal of the controversy of Dax and Broca. J. Hist. Neurosci. 3, 215-226. doi: 10.1080/09647049409525614

Dax, M. (1836). Lésions de la moitié gauche de l'encéphale coïncidant avec l'oubli des signes de la pensée (lu á Montpellier en 1836). Bull. Hebd. Med. Chir. 2, 259-262.

De Jaegher, H., Di Paolo, E., and Gallagher, S. (2010). Can social interaction constitute social cognition? Trends Cogn. Sci. 14, 441-447. doi: 10.1016/j.tics.2010.06.009

Driver, J., and Noesselt, T. (2008). Multisensory interplay reveals crossmodal influences on 'sensory-specific' brain regions, neural responses, and judgments. Neuron 57, 11-23. doi: 10.1016/j.neuron.2007.12.013

Fodor, J. A. (1983). The modularity of mind. Cambridge, MA: MIT Press.

Franzen, M. D., and Wilhelm, K. L. (1996). "Conceptual foundations of ecological validity in neuropsychological assessment," in Ecological Validity of Neuropsychological Testing, eds R. J. Sbordone and C. J. Long (Boca Raton, FL: St. Lucie Press), 91-112.

Freund, P., Friston, K., Thompson, A. J., Stephan, K. E., Ashburner, J., Bach, D. R., et al. (2016). Embodied neurology: an integrative framework for neurological disorders. Brain 139, 1855-1861. doi: 10.1093/brain/aww076

Fuchs, T. (2009). Embodied cognitive neuroscience and its consequences for psychiatry. Poiesis Prax. 6, 219-233. doi: 10.1007/s10202-008-0068-9

Fuchs, T., and Schlimme, J. E. (2009). Embodiment and psychopathology: a phenomenological perspective. Curr. Opin. Psychiatry 22, 570-575. doi: 10.1097/YCO.0b013e3283318e5c

Fuster, J. M., Bodner, M., and Kroger, J. K. (2000). Cross-modal and crosstemporal association in neurons of frontal cortex. Nature 405, 347-351. doi: $10.1038 / 35012613$ 
Gallese, V., and Lakoff, G. (2005). The Brain's concepts: the role of the Sensorymotor system in conceptual knowledge. Cogn. Neuropsychol. 22, 455-479. doi: $10.1080 / 02643290442000310$

Gallese, V., and Sinigaglia, C. (2011). What is so special about embodied simulation? Trends Cogn Sci. 15, 512-519. doi: 10.1016/j.tics.2011.09.003

Ghazanfar, A. A., and Schroeder, C. E. (2006). Is neocortex essentially multisensory? Trends Cogn Sci. 10, 278-285. doi: 10.1016/j.tics.2006.04.008

Goldberg, E. (1989). Gradiental approach to neocortical functional organization. J. Clin. Exp. Neuropsychol. 11, 489-517. doi: 10.1080/01688638908400909

Goldberg, E. (1995). Rise and fall of modular orthodoxy. J. Clin. Exp. Neuropsychol. 17, 193-208. doi: 10.1080/01688639508405118

Golden, C. J., Hammeke, T. A., and Purisch, A. D. (1980). The Luria-Nebraska battery manual. Los Angeles, CA: Western Psychological Services.

Goldin-Meadow, S., and Beilock, S. L. (2010). Action's influence on thought: the case of gesture. Perspect. Psychol. Sci. 5, 664-674. doi: $10.1177 / 1745691610388764$

Gonzalo, J. (1950). Investigaciones Sobre la Nueva Dinámica Cerebral. La Actividad Cerebral en Función de las Condiciones Dinámicas de la Excitabilidad Nerviosa. Madrid: Consejo Superior de Investigaciones Científicas.

Gonzalo-Fonrodona, I. (2009). Functional gradients through the cortex, multisensory integration and scaling laws in brain dynamics. Neurocomputing 72, 831-838. doi: 10.1016/j.neucom.2008.04.055

Halstead, W. C. (1947). Brain and Intelligence; A Quantitative Study of the Frontal Lobes. Chicago, IL: University of Chicago Press.

Hanson-Vaux, G., Crisinel, A. S., and Spence, C. (2013). Smelling shapes: crossmodal correspondences between odors and shapes. Chem. Senses 38, 161-166. doi: 10.1093/chemse/bjs087

Hartlage, L. (1966). Common psychological tests applied to the assessment of brain damage. J. Proj. Tech. Pers. Assess. 30, 317-338. doi: 10.1080/0091651X.1966.10120322

Ibáñez, A., Cardona, J. F., Dos Santos, Y. V., Blenkmann, A., Aravena, P., Roca, M., et al. (2013). Motor-language coupling: direct evidence from early Parkinson's disease and intracranial cortical recordings. Cortex 49, 968-984. doi: 10.1016/j.cortex.2012.02.014

Ibáñez, A., and Manes, F. (2012). Contextual social cognition and the behavioral variant of frontotemporal dementia. Neurology 78, 1354-1362. doi: 10.1212/WNL.0b013e3182518375

Ibáñez, A., Riveros, R., Aravena, P., Vergara, V., Cardona, J. F., García, L., et al. (2011). When context is difficult to integrate: cortical measures of congruency in schizophrenics and healthy relatives from multiplex families. Schizophr Res. 126, 303-305. doi: 10.1016/j.schres.2010.04.008

Kargieman, L., Herrera, E., Baez, S., García, A. M., Dottori, M., Gelormini, C., et al. (2014). Motor-language coupling in Huntington's disease families. Front. Aging Neurosci. 6:122. doi: 10.3389/fnagi.2014.00122

Klapetek, A., Ngo, M. K., and Spence, C. (2012). Does crossmodal correspondence modulate the facilitatory effect of auditory cues on visual search? Atten. Percept. Psychophys. 74, 1154-1167. doi: 10.3758/s13414-012-0317-9

Lashley, K. S. (1929). Brain Mechanism and Intelligence. Chicago, IL: University of Chicago Press.

Lezak, M. D. (2012). Neuropsychological Assessment, 5 Edn, New York, NY: Oxford University Press.

Magendie, F. (1822). Expériences sur les fonctions des racines des nerfs qui naissent de la moelle épinière. J. Physiol. Exp. Pathol. 2, 366-371.

Manning, L., and Thomas-Anterion, C. (2011). Marc Dax and the discovery of the lateralisation of language in the left cerebral hemisphere. Rev. Neurol. 167, 868-872. doi: 10.1016/j.neurol.2010.10.017

McDonald, S., Flanagan, S., Rollins, J., and Kinch, J. (2003). TASIT: a new clinical tool for assessing social perception after traumatic brain injury. J. Head Trauma Rehabil. 18, 219-238. doi: 10.1097/00001199-20030500000001

Moscovitch, M. (1995). Recovered consciousness: a hypothesis concerning modularity and episodic memory. J. Clin. Exp. Neuropsychol. 17, 276-290. doi: $10.1080 / 01688639508405123$

Moscovitch, M., and Nachson, I. (1995). Modularity and the brain. Intro. J. Clin. Exp. Neuropsychol. 17, 167-170. doi: 10.1080/01688639508405116

Neary, D., Snowden, J. S., and Mann, D. M. (2000). Cognitive change in motor neurone disease/amyotrophic lateral sclerosis (MND/ALS). J. Neurol. Sci. 180, 15-20. doi: 10.1016/S0022-510X(00)00425-1
Niedenthal, P. M. (2007). Embodying emotion. Science 316, 1002-1005. doi: $10.1126 /$ science. 1136930

Parise, C. V., and Spence, C. (2012). Audiovisual crossmodal correspondences and sound symbolism: a study using the implicit association test. Exp. Brain Res. 220, 319-333. doi: 10.1007/s00221-012-3140-6

Péran, P., Démonet, J. F., Pernet, C., and Cardebat, D. (2004). Verb and noun generation tasks in Huntington's disease. Mov. Disord. 19, 565-571. doi: $10.1002 / \mathrm{mds} .10706$

Peretz, I., and Coltheart, M. (2003). Modularity of music processing. Nat. Neurosci. 6, 688-691. doi: 10.1038/nn1083

Peretz, I., Kolinsky, R., Tramo, M., Labrecque, R., Hublet, C., Demeurisse, G., et al. (1994). Functional dissociations following bilateral lesions of auditory cortex. Brain 117, 1283-1301. doi: 10.1093/brain/117.6.1283

Pinker, S., and Ullman, M. T. (2002). The past and future of the past tense. Trends Cogn. Sci. 6, 456-463. doi: 10.1016/S1364-6613(02)01990-3

Pribram, K. H. (1971). Languages of the Brain. Upper Saddle River, NJ: PrenticeHall.

Proffitt, D. R. (2006). Embodied perception and the economy of action. Perspect. Psychol. Sci. 1, 110-122. doi: 10.1111/j.1745-6916.2006.00008.x

Pulvermüller, F. (2005). Brain mechanisms linking language and action. Nat. Rev Neurosci. 6, 576-582. doi: 10.1038/nrn1706

Rabin, L. A., Burton, L. A., and Barr, W. B. (2007). Utilization rates of ecologically oriented instruments among clinical neuropsychologists. Clin. Neuropsychol. 21, 727-743. doi: 10.1080/13854040600888776

Reitan, R. M., and Wolfson, D. (1985). Halstead-Reitan Neuropsychological test battery: Theory and Clinical Interpretation. Tucson, AZ: Neuropsychology Press.

Reitan, R. M., and Wolfson, D. (1993). The Hasltead-Reitan Neuropsychological Test Battery: Theory and Clinical Interpretation.. Tucson, AZ: Neuropsychology Press.

Rizzolatti, G., and Arbib, M. A. (1998). Language within our grasp. Trends Neurosci. 21, 188-194. doi: 10.1016/S0166-2236(98)01260-0

Rizzolatti, G., and Craighero, L. (2004). The mirror-neuron system. Аnnu. Rev. Neurosci. 27, 169-192. doi: 10.1146/annurev.neuro.27.070203. 144230

Sammer, G., Reuter, I., Hullmann, K., Kaps, M., and Vaitl, D. (2006). Training of executive functions in Parkinson's disease. J. Neurol. Sci. 248, 115-119. doi: 10.1016/j.jns.2006.05.028

Shallice, T. (1988). From Neuropsychology to Mental Structure. New York, NY: Cambridge University Press.

Silveri, M. C., and Ciccarelli, N. (2007). The deficit for the word-class "verb" in corticobasal degeneration: linguistic expression of the movement disorder? Neuropsychologia 45, 2570-2579. doi: 10.1016/j.neuropsychologia.2007. 03.014

Sinforiani, E., Banchieri, L., Zucchella, C., Pacchetti, C., and Sandrini, G. (2004). Cognitive rehabilitation in Parkinson's disease. Arch Gerontol. Geriatr. 9(Suppl.1), 387-391. doi: 10.1016/j.archger.2004. 04.049

Spence, C., and Parise, C. V. (2012). The cognitive neuroscience of crossmodal correspondences. Iperception 3, 410-412. doi: 10.1068/i0540ic

Strauss, E., Sherman, E. M., and Spreen, O. (2006). A Compendium of Neuropsychological Tests: Administration, Norms and Commentary, 3rd Edn., New York, NY: Oxford University Press.

Teuber, H. L. (1955). Physiological psychology. Annu. Rev. Psychol. 6, 267-296. doi: 10.1146/annurev.ps.06.020155. 001411

Torralva, T., Roca, M., Gleichgerrcht, E., Bekinschtein, T., and Manes, F. (2009). A neuropsychological battery to detect specific executive and social cognitive impairments in early frontotemporal dementia. Brain 132, 1299-1309. doi: 10.1093/brain/awp041

Warrington, E. K., and McCarthy, R. A. (1987). Categories of knowledge. Further fractionations and an attempted integration. Brain 110, 1273-1296. doi: 10.1093/brain/110.5.1273

Warrington, E. K., and Shallice, T. (1984). Category specific semantic impairments. Brain 107, 829-854. doi: 10.1093/brain/107.3.829

Weiskrantz, L. (1968). "Treatments, inference and brain function," in Analysis of Behavioural Change, ed L. Weiskrantz (New York, NY: Harper and Row), 400-414. 
Weiskrantz, L. (1991). "Dissociations and associates in neuropsychology," in Perspectives in Cognitive Neuroscience, ed R. G. Lister (New York, NY: Oxford University Press), 847-864.

Willems, R. M., and Francken, J. C. (2012). Embodied cognition: taking the next step. Front. Psychol. 3:582. doi: 10.3389/fpsyg.2012. 00582

Wilson, B. A., Cockburn, J., and Baddeley, A. (1985). The Rivermead Behavioral Memory Test. Reading, England: Thames Valley Test Co. Gaylord, MI: National Rehabilitation Services.

Wilson, B. A., Cockburn, J., and Halligan, P. (1987). Behavioural Inattention Test. Titchfield, Fareham, Hants, England: Thames Valley Test Co. Gaylord, MI: National Rehabilitation Services.

Witt, J. K. (2011). Action's effects on perception. Curr. Dir. Psychol. Sci. 20, 201-206. doi: 10.1177/0963721411408770
Zatti, A., and Zarbo, C. (2015). Embodied and exbodied mind in clinical psychology. A proposal for a psycho-social interpretation of mental disorders. Front. Psychol. 6:236. doi: 10.3389/fpsyg.2015.00236

Conflict of Interest Statement: The author declares that the research was conducted in the absence of any commercial or financial relationships that could be construed as a potential conflict of interest.

Copyright $(2017$ Cardona. This is an open-access article distributed under the terms of the Creative Commons Attribution License (CC BY). The use, distribution or reproduction in other forums is permitted, provided the original author(s) or licensor are credited and that the original publication in this journal is cited, in accordance with accepted academic practice. No use, distribution or reproduction is permitted which does not comply with these terms. 